\title{
REDESIGNING A CASE STUDY FOR THE ASSESSMENT OF ETHICAL RESPONSIBILITY
}

\author{
Andrés Boza, Marta Fernández-Diego, Llanos Cuenca, Leonor Ruiz \\ School of Informatics. Universitat Politècnica de València (SPAIN)
}

\begin{abstract}
This work presents the redesign of an activity (case study) that has been carried out over the last three years in the course Deontology and Professionalism for 2nd year students of the Informatics Engineering Degree at the Universitat Politècnica de València (UPV) -Spain-.

The aim of the activity is to encourage students to face ethical dilemmas that they may encounter in the exercise of their profession. Specifically, the case is about autonomous cars where decisions that must be taken imply a challenge, and even more when the programmers of the car deal with situations where human lives are endangered.
\end{abstract}

The UPV has defined some general scoring rubrics in order to assess transversal competences of students. One of these rubrics deals with Ethics. Indicators included in this rubric are:

The student:

- Becomes aware of other ways of seeing and perceiving things

- Critically accepts new perspectives, although this requires questioning your own perspective

- Differentiates facts from opinions in the arguments of other people

- Reflects on the consequences and effects (practical implications) that decisions and proposals have on people

- Recognizes the ethical and deontological aspects of the profession

The case is introduced in a progressive way facilitating the development of the ethical competence and includes the required elements to assess the indicators established in the rubric. Thus, all the indicators proposed in the rubric can be evaluated by means of this activity.

As a conclusion, the high degree of participation of the students in the activity is remarkable, which is on the one hand due to the transcendence of the theme and on the other hand because it is a very current topic closely linked to the computer science. Furthermore, the redesign of the case guided by the rubric allows an adequate evaluation.

Keywords: Design of activities, Scoring rubrics, Assessment of competences, Case studies.

\section{INTRODUCTION}

Ethical responsibility in the practice of a profession (and in any other area of our lives) is an aspect that educational institutions require for future graduates. In order to reinforce this attitude in the students, some bachelor and master degrees include contents related to deontology in a subject or in a set of subjects as a transversal perspective.

The Informatics Engineering Degree at the Universitat Politècnica de València (UPV) participates in this purpose and this degree includes the subject "Deontology and Professionalism" where these topics are addressed. But, in addition, this bachelor degree participates in an institutional project on Transversal Competences of the UPV where one of the competence (considered important for our students) is the "Ethical, Environmental and Professional Responsibility".

\subsection{Transversal competences}

Transversal competences are generic and transferable in a wide variety of personal, social, academic and professional contexts throughout life. Therefore, they contribute to a fundamental part of the professional profile and educational profile in all the bachelor and master degrees. These competences include a set of cognitive and metacognitive skills, and, attitudinal and instrumental knowledge, which has a great value to the knowledge society. 
The UPV has created an institutional project about transversal competences $[1,2]$. The objective of this project is to accredit a defined set of transversal competences in all the graduated students. The project consists on 1) establishing a strategy for the systematic evaluation of transversal competences, defining where they are acquired and how they should be evaluated, and 2) accrediting the acquisition of these competences.

The set of transversal competences in the project include 13 competences: CT-01. Comprehension and integration, CT-02. Application and practical thinking, CT-03. Analysis and problem solving, CT04. Innovation, creativity and entrepreneurship, CT-05. Design and project, CT-06. Teamwork and leadership, CT-07. Ethical, environmental and professional responsibility, CT-08. Effective communication, CT-09. Critical thinking, CT-10. Knowledge of contemporary problems, CT-11. Permanent learning, CT-12. Planning and time management, CT-13. Specific instruments.

This paper deals with the Ethical, environmental and professional responsibility competence.

\subsubsection{Ethical, environmental and professional responsibility competence}

This competence refers to the set of knowledge, abilities, skills and attitudes, useful for interacting with the environment, in an ethical, responsible and sustainable manner, in order to avoid or diminish the negative effects produced by the inadequate practices caused by human activity and to promote the benefits that can generate the professional activity in the environmental field, taking into account its economic and social implications. Ethical responsibility refers to guiding human action in a rational sense, so it is related to actions and its moral value. Environmental responsibility is the attribution of a positive or negative assessment of the ecological impact of a decision. Generally, it refers to damage caused to other species, nature or future generations by the actions (or non-actions) of a person or group of people. Professional responsibility arises at this point with two primary objectives: to avoid any voluntary failure and to reduce, as far as possible, the number of involuntary faults [3]

This competence has been treated in two dimensions: on the one hand, ethical and professional responsibility and, on the other hand, environmental responsibility. The ethical and professional dimension in a first domain (level 1 for $1^{\text {st }}$ and $2^{\text {nd }}$ year) establishes:

To question reality and to be aware of the concepts and values from which it is constructed.

Indicators:

1 Becomes aware of other ways of seeing and perceiving things

2 Critically accepts new perspectives, although this requires questioning your own perspective

3 Differentiates facts from opinions in the arguments of other people

4 Reflects on the consequences and effects (practical implications) that decisions and proposals have on people

5 Recognizes the ethical and deontological aspects of the profession

This first domain (and indicators) has been defined for subjects in $1^{\text {st }}$ and $2^{\text {nd }}$ year for the UPV. In our case the subject was "Deontology and Professionalism".

\subsection{Deontology and Professionalism subject}

In this increasingly digital society, informatics have evolved from being considered as peripheral to be positioned in the center of any sphere of human relationships. Indeed, computer science is everywhere, in health, in commerce, in state security forces, in industry, transports... Computer engineers manage information, which is not always translated into power as the saying goes, but in issues and concerns for the rest of citizens. Time passes and much more for informatics: advances in information technology often get a speed faster than in other sciences. This causes a dynamism that is inconceivable in other sectors.

This course is located in the second year of the Informatics Engineering Degree. It is divided into three parts: "Professionalism", "Legal aspects" and "Ethics", although they are intertwined with each other, making it difficult to determine an order. 


\subsubsection{Professionalism}

To this end, this part starts from a study of the profession in general to quickly particularize in informatics. The subject passes over the story of informatics: when informatics began to be aware of its existence, detached from other professions.

\subsubsection{Legal aspects}

In this part of the course, the subject gives an insight into those major facets of this profession subject to law, considering the main standards. Obviously, it is impossible to make a summary including with completeness each and every law, regulation and other legal precepts affecting the profession. Hence the subject focuses the attention on those areas that receive more interest in terms of both the attention given by the courts and the impact on civil society, with an interest generally redirected by the media. Since all exclusions necessarily imply selection, as far as possible and following the basic lines of this part of the course, the subject tries to cover at least the basic legal framework for good professional practice.

\subsubsection{Deontology and ethics}

The subject introduces ethics and its relationship with the company and, above all, with computing profession. The reason for its inclusion is elementary: if it is true that the law marks a few channels of action, but the last barrier, which marks us those thin red lines not to cross, is called ethics.

As it is an unusual subject for a career in technology, it is convenient to start from the establishment of some basic concepts, and then discuss the business ethics without forgetting individual ethics or society ethics in general. The subject introduces key issues such as the social balance or the codes of ethics, and, of course, it places particular emphasis on the relationship between ethics and computing science.

\section{METHODOLOGY}

This work presents the redesign of an activity (case study) that had been carried out over the last three years in the course Deontology and Professionalism.

The aim of the activity is to encourage students to face ethical dilemmas that they may encounter in the exercise of their profession. Specifically, the case is about autonomous cars where decisions that must be taken imply a challenge, and even more when the programmers of the car deal with situations where human lives are endangered.

\subsection{Autonomous cars case}

Nowadays, the autonomous cars are being object of study by an important number of companies. Every time seems to be closer the idea of autonomous cars that drive without a human being behind the wheel.

New hardware and software components are equipped in cars to achieve this objective. Sensors, cameras, radars or GPS are included in vehicles to collect data periodically with the proposal of obtaining a map of its environment. The algorithms responsible for making decisions on driving handle quite diverse information from different sources. Algorithms try to anticipate the unpredictable situations of traffic in real time environment. A possible car accident where a group of pedestrians are involved could imply a tragic (software) decision for the occupant of the vehicle. How is this moral or ethical programming taken into account? If the algorithm has to decide to hit a motorcycle rider with a helmet or other rider without a helmet, which one should "choose" the programming? [4]

It seems clear that the rate of danger situations should be lower because, apparently, the autonomous car would be much more prudent and would not be distracted. However it is impossible to avoid all dangerous situations at the wheel. In the case of an autonomous car, decisions in a situation of danger would be cold, very different from hot decisions based on reflexes and almost instantaneous decisions that would take the driver, and that society accepts whatever its outcome.

\subsection{Case study redesign for the assessment of ethical responsibility}

The case developed in the classroom was redesigned to evaluate the ethical and professional dimension according to the suggested indicators: 


\subsubsection{Becomes aware of other ways of seeing and perceiving things}

Students are divided in two groups. The first group (G1) remains in the classroom and the second group (G2) leaves the classroom to not hear what is in it.

For $\mathrm{G} 1$ the following situation is presented to them:

Imagine that you are responsible for a space mission. The ship manned by a space scientist is returning to the earth, but at its entrance to the atmosphere the driving control of the ship is lost and it does not respond to redirect its trajectory. The vehicle is going to crash irreparably against a school and the sensors of the ship detect 6 people inside the school.

You are responsible for the space mission and from your control station you can destroy the ship. What would you do? Do you destroy the ship before crashing against the school (then you save the 6 people but the pilot die) or drop the ship saving the pilot (then you save the pilot but 6 people die)?

For $\mathrm{G} 2$ the following situation is presented to them:

Imagine that you are driving through a mountain area where the road edges a very pronounced valley. You may be driving at a higher speed than recommended for this type of road. You are entering in a curve, and then, you find 6 people crossing on the middle of the road. You do not have time to react, your options are to leave the road and fall down into the deep valley below to avoid the accident (then you save the 6 people but you die) or run over the 6 people (then you are saved but 6 people die).

A debate is performed inside each group.

Question for the indicator assessment:

Can you understand those who defend other position even if you do not coincide with theirs ideas?

This question reveals if the student is able to understand on the one hand that it is not an easy question and on the other hand to accept the plurality of ideas.

Results: In spite of the internal debate they are usually fixed in their initial positions.

The usual results found in each group are:

G1: The majority response is "to destroy the ship, and then, to save the people who are in school."

G2: The majority response is "to run over the group and save yourself"

\subsubsection{Critically accepts new perspectives, although this requires questioning your own perspective}

The two groups are invited to make a global debate.

Question for the indicator assessment:

How has your point of view changed after hearing the other group opinions?

The group of 6 people at risk has very different consequences in each one of the situations. The main difference lies in the decision maker's position. If the decision maker is inside the vehicle, he or she makes a different decision than when he or she is out and the consequences of the decision affect to a third person but do not affect him/her.

Results: It is in the confrontation with the other group when they begin to meditate more about their positions.

\subsubsection{Differentiates facts from opinions in the arguments of other people}

Students are invited to analyse about the discussion in the debate.

Question for the indicator assessment:

Differentiate between properly argued opinions and unjustified opinions.

Results: The majority of the students can differentiate argued opinions from unjustified opinions even when these are different from their own opinions. 


\subsubsection{Reflects on the consequences and effects (practical implications) that decisions and proposals have on people}

Question for the indicator assessment:

Does it have implications to obtain more/new information about the environment? If yes, give an example.

Results: Students provide new factors to take into account: vehicle speeds, type of vehicle, number of people affected, age of persons, were pedestrians passing by a zebra crossing? or were they jumping a traffic red light for pedestrians?

Should minimizing damage be the unique criterion?

Results:

Students extend their reflexions to include instinctive human decision (where random factors are involved).

\subsubsection{Recognizes the ethical and deontological aspects of the profession}

A possible future professional career for our students is as software developers.

Question for the indicator assessment:

Do you think these ethical dilemmas can be found in your future career?

How would you act if you had to develop an algorithm that manages a similar situation (for example an autonomous car)?

Do you think the algorithm should be universal (reaching consensus)? or Should each manufacturer have its own algorithm?

How would you act if you were asked to develop an algorithm whose philosophy does not correspond to your way of thinking?

Do you think the algorithm should be secret or would be more interesting a free software solution?

Results: The set of questions tries to evaluate aspects related to the exercise of his/her profession and the student think about on the consequences of theirs works for third parties.

\section{CONCLUSIONS}

As a conclusion, the high degree of participation of the students in the activity is remarkable, which is on the one hand due to the transcendence of the theme and on the other hand because it is a very current topic closely linked to the computer science.

This case has been previously used to introduce students into ethical aspects, and more specifically, to face ethical dilemmas that they may encounter in the exercise of their profession.

Redesigning the case study guided by the indicators defined for the Ethical, environmental and professional responsibility competence has allowed:

- To extend the case study and to include new perspectives into the case.

- To organize the case study according to the indicators defined in the competence.

- To obtain evidences in order to make an adequate evaluation of the indicators.

- To deploy the case study customised, that means, to select only specific questions according to the indicator (or indicators) that we want to evaluate.

\section{ACKNOWLEDGEMENTS}

This research has been carried out under the project of innovation and educational improvement (PIME/A15) 'DAICE - Design of activities for the Innovation, Creativity and Entrepreneurship Competence' funded by the Universitat Politècnica de València, and the Escola Tècnica Superior d'Enginyeria Informàtica. 


\section{REFERENCES}

[1] Universitat Politècnica de Valencia, "Conoce el Proyecto de Competencias Transversales UPV." http://competenciast.webs.upv.es/, 2017.

[2] Alemany A., L. Cuenca, A. Boza, M. Fernández-Diego, L. Ruiz, F. Alarcón, M.L. Gordo (2016) INNOVATION PROJECTS ASSOCIATED TO THE COMPETENCE OF INNOVATION, CREATIVITY AND ENTREPRENEURSHIP IN THE UNIVERSITAT POLITĖCNICA DE VALĖNCIA, INTED2016 Proceedings, pp. 2903-2907.

[3] U. P. de València, "RESPONSABILIDAD ÉTICA, MEDIOAMBIENTAL Y PROFESIONAL." http://www.upv.es/contenidos/COMPTRAN/info/954882normalc.html.

[4] J. Pastor, "el-coche-del-futuro-quizas-te-sacrifique-para-salvar-vidas @ www.xataka.com." https://www.xataka.com/automovil/el-coche-del-futuro-quizas-te-sacrifique-para-salvar-vidas. 